\title{
Speed Management in Rural Roads in Greece
}

\author{
Basil Psarianos ${ }^{1}$ and Nikiforos Stamatiadis ${ }^{2}$ \\ 1. National Technical University of Athens, Greece \\ 2. University of Kentucky, Lexington, KY 40506-0281, USA
}

\begin{abstract}
Setting reliable speed limits on roads has always been a challenging process of designers and road agencies. In this paper the results of a methodology for setting speed limits on rural roads of all categories in Greece is presented based on international research and an extensive drivers attitudes' survey. The 85th percentile speed has proven in this case to be the decisive criterion for establishing reliable speed limits or advisory speeds in most cases. The resulted $10 \mathrm{~km} / \mathrm{h}$ increase in legal speed limits on freeways and express rural highways did not validate any fears that accident rates or frequencies would increase. On the contrary an $8 \%$ decrease of crashes was observed in a period of about three years after the implementation of the increased speed limits level on the rural highway network of the country.
\end{abstract}

Key words: Speed limits, operating speeds, 85th percentile speed, rural highways.

\section{Introduction}

Speed remains one of the most important and critical design and operating parameter in highway engineering. Speed limit is a speed measure that is communicated to all roadway users (drivers, designers, and law enforcement) in a explicit and unquestionable manner. The importance of the speed limit has lately been recognized as the critical design parameter of contemporary design guides and policies replacing the old definition of design speed which has been proven to be a vague and questionable design parameter [1].

Speed limits are directly associated with operating speeds and more specifically the 85th percentile speed of uninterrupted, free flow speed on a wet but clean pavement. This association has an impact on road safety [2-6]. It is widely accepted that failure to correctly select the appropriate operating speed can lead to a crash. Therefore, the selection of the proper operating speed based on existing posted speed limits should be viewed as a major component in addressing roadway safety. This implicitly implies that any changes in the operating speed should be timely

Corresponding author: Nikiforos Stamatiadis, PhD, PE, professor, research fields: CE/Transportation. E-mail: nstamat@engr.uky.edu. communicated to the drivers. The establishment of a posted speed limit based on this principle is often viewed by several countries as a "prima facie" legal measure. This approach entails the concept that a posted speed limit is reflection of the appropriate operating speed of a vehicle and therefore a prudent choice of a driver for the given roadway environment and conditions. It is apparent that a single posted speed limit cannot address all conditions and scenarios that a driver has to deal with while moving through a roadway section.

It is imperative that posted speed limits should be set in a technically and scientific sound manner. Such an approach should result in a roadway environment that will not rely on posted speed limit signs to enforce arbitrary chosen speeds but on posted speed limit signs that are sensible and are in agreement with the roadway environment and driver's expectation as far as possible.

Understanding of how drivers view posted speed limits is a prerequisite for setting up a methodology for establishing appropriate speed limits. Using this understanding, a methodology can be developed on establishing reliable and acceptable speed limits. This paper describes the results from such an approach, where first the attitudes of Greek drivers on rural roads 
were investigated and then used to develop a methodology for setting speed limits on these roads.

\section{Attitudes of Greek Drivers towards Posted Speed Limits}

A total of 402 driver surveys were completed (294 passenger cars and 108 trucks) at various locations along the Greek national highway system. The surveys completed for freeways were conducted at toll booths and were completed as the drivers stopped to pay the toll. Speed measurements were not taken at these locations due to the influence of the toll collection stations but at other representative free-flow locations.

\subsection{Freeways}

2.1.1 Passenger Cars with a Legal Speed Limit 120 $\mathrm{km} / \mathrm{h}$

The first group of speeds analyzed dealt with passenger cars. The results indicate the average speed of drivers was $131 \mathrm{~km} / \mathrm{h}$ and only $43 \%$ of the drivers did not exceed the posted speed limit of $120 \mathrm{~km} / \mathrm{h}$. The speed data indicated that the 85 th percentile speed is $145 \mathrm{~km} / \mathrm{h}$, only a third of the drivers travel at the posted speed limit of $120 \mathrm{~km} / \mathrm{h}$, and $40 \%$ of the drivers travel at speeds equal to or greater than $140 \mathrm{~km} / \mathrm{h}$.

The data of the surveys indicate that drivers who are familiar with the roadway have a tendency to drive at higher speeds (average speeds of $137 \mathrm{~km} / \mathrm{h}$ ) while those who travel less frequent had lower average speeds $(118 \mathrm{~km} / \mathrm{h})$. As a percentage, $62 \%$ of the drivers familiar with the roadway exceeded the posted speed limit while only $12 \%$ of those unfamiliar traveled at speeds greater than $120 \mathrm{~km} / \mathrm{h}$ (the posted speed limit).

Regarding speed enforcement, approximately one third of drivers have received a citation for speeding and they had an average speed of $139 \mathrm{~km} / \mathrm{h}$. On the contrary, those who exceed the posted speed but not received a citation had a lower overall average speed $(127 \mathrm{~km} / \mathrm{h})$ possibly indicating a tolerance of the police to issue citations for smaller infractions.
Safety was cited as the major reason for complying to posted speed limits while legal implications and risk for citations received lower scores in preference survey. A large percentage of drivers indicated that safety is the main reason for not speeding and their speeds reflected this: their average speed was $124 \mathrm{~km} / \mathrm{h}$. Two thirds of the drivers consider the existing posted speed limit of $120 \mathrm{~km} / \mathrm{h}$ as low and cited a necessity to increase it. The mean speed of those drivers is $138 \mathrm{~km} / \mathrm{h}$. Drivers who consider that the current posted speed limit is about correct ( $31 \%$ of the drivers) traveled at a mean speed of $120 \mathrm{~km} / \mathrm{h}$. Only $5 \%$ of the drivers believe that the speed limit is very high and needs to be decreased.

One half of the drivers interviewed believe that the posted speed limit should not be exceeded even though most of them drive at higher speeds. A surprising answer was the notion that two thirds of the drivers believe that the posted speed limit can be exceeded at certain situations and that speeds can be safe within a $10 \mathrm{~km} / \mathrm{h}$ range of the posted speed limit. Another unanticipated answer was that one third of drivers believe that the current posted speed limits are lower than a perceived safety speed and they can exceed it by more than $10 \mathrm{~km} / \mathrm{h}$. One fifth of drivers consider that the current posted speed limits are incorrect since they believe that they should be able to decide to drive faster or slower. Those drivers exceed the existent speed limit by an average of $15 \mathrm{~km} / \mathrm{h}$. More that two thirds (68\%) of the drivers disagree with the speed limit of $120 \mathrm{~km} / \mathrm{h}$ on freeways and drive with a mean speed of $129 \mathrm{~km} / \mathrm{h}$.

\subsubsection{Trucks with a Legal Speed Limit $80 \mathrm{~km} / \mathrm{h}$}

The second group of drivers dealt with trucks. More than one half (58\%) of truck drivers did not exceed the posted speed limit of $80 \mathrm{~km} / \mathrm{h}$, they have an average speed of $84 \mathrm{~km} / \mathrm{h}$, and their 85 th percentile speed is 90 $\mathrm{km} / \mathrm{h}$. Only a small portion $(10 \%)$ travel at speeds higher than $90 \mathrm{~km} / \mathrm{h}$.

The frequency of driving on freeways does not have any significant impact on truck drivers' speed as was noted for passenger car drivers. They also agree with passenger cars drivers ( $85 \%$ of truck drivers) on the 
aspect of safety for complying with posted speed limits. Those drivers exceed the speed limit by $4 \mathrm{~km} / \mathrm{h}$ and their speed is equal with the mean speed of the drivers that do not consider safety as an important reason for complying with speed limits. A small fraction of drivers $(31 \%)$ have received speeding citations and their speeds are slightly higher $(84.8 \mathrm{~km} / \mathrm{h})$ than those who have not received a citation $(84.0 \mathrm{~km} / \mathrm{h})$.

Almost two thirds of truck drivers consider that the speed limit $(80 \mathrm{~km} / \mathrm{h})$ is very low and must be increased. The mean speed for those drivers is $86 \mathrm{~km} / \mathrm{h}$. The remaining (38\%) drivers consider that the existent speed limit is about correct and they drive with a mean speed of $81 \mathrm{~km} / \mathrm{h}$. None of the drivers interviewed believes that the speed limit is very high and needs to be decreased.

A large portion (60\%) of truck drivers also consider that the speed limit on freeways must not be exceeded although a high percentage of them drive little faster than $80 \mathrm{~km} / \mathrm{h}$. There is again a large portion (58\%) of the drivers who consider that the speed limit can be exceeded only on certain situations and they drive with average speed of $86 \mathrm{~km} / \mathrm{h}$. An even larger percentage $(74 \%)$ of drivers agrees with the aspect that the speed limit of $80 \mathrm{~km} / \mathrm{h}$ is lower than a safety speed and it can be exceeded up to $10 \mathrm{~km} / \mathrm{h}$. The mean speed for those drivers is $86 \mathrm{~km} / \mathrm{h}$. Almost one fifth (17\%) of drivers consider that speed limit of $80 \mathrm{~km} / \mathrm{h}$ is lower than the safety limit of driving and can be exceeded more than $10 \mathrm{~km} / \mathrm{h}$. The mean speed for those drivers is $89 \mathrm{~km} / \mathrm{h}$.

\subsection{Two-Lane Rural Roads}

2.2.1 Passenger Cars with Legal Speed Limit 90 $\mathrm{km} / \mathrm{h}$

Almost two-thirds (65\%) of the drives exceeded the posted speed limit, their average speed was $103 \mathrm{~km} / \mathrm{h}$, and the 85 th percentile speed was $120 \mathrm{~km} / \mathrm{h}$. A large portion $(35 \%)$ of drivers travel at speeds equal to or greater than $110 \mathrm{~km} / \mathrm{h}$.

The frequency of driving on such roads had little effect on the drivers' speed choice. Those who use them on a daily basis recorded an average speed of 110 $\mathrm{km} / \mathrm{h}$ while those who use them less frequently had a speed of $100 \mathrm{~km} / \mathrm{h}$. The mean speed of drivers that have received a speeding citation is higher than the speed of drivers that have not cited for speeding. However, speeding citations are not a significant deterrent mainly due to the spotty and inconsistent speed enforcement.

Drivers again noted that the most important reason for complying with posted speed limits is safety. For these roads almost one half $(46 \%)$ of the drivers stated that the posted speed limit is very low and must be increased. The mean speed for those drivers is 110 $\mathrm{km} / \mathrm{h}$. Almost an equal percentage (48\%) consider that the existent posted speed limit is about correct and they drive on average with $98 \mathrm{~km} / \mathrm{h}$. Only $6 \%$ of the drivers believe that the speed limit is high and must be decreased. The mean speed for those drivers is 88 $\mathrm{km} / \mathrm{h}$.

The concept of exceeding the posted speed limit on certain situations was also prominent on these roadways. Almost two thirds $(63 \%)$ of the drives believe this to be the case. The relationship of the posted speed limit to a safety speed was also investigated indicating that $65 \%$ of the drivers consider the $90 \mathrm{~km} / \mathrm{h}$ speed limit low and that it could be safely exceeded up to $10 \mathrm{~km} / \mathrm{h}$. The mean speed for those drivers is $100 \mathrm{~km} / \mathrm{h}$. A large percentage $(38 \%)$ of drivers also believe that the posted speed limit is lower than the safety speed and exceeding the speed limit by more than $10 \mathrm{~km} / \mathrm{h}$ is acceptable.

\subsubsection{Trucks with Legal Speed Limit $80 \mathrm{~km} / \mathrm{h}$}

A very large (87\%) percentage of drivers did not exceed the posted speed limit. The speed data indicate an average speed of $76.6 \mathrm{~km} / \mathrm{h}$ and an 85 th percentile speed of $80 \mathrm{~km} / \mathrm{h}$ : at the posted speed limit for trucks.

Safety was cited again as the primary reason for complying with the posted speed limits. A small portion $(19 \%)$ of the drivers considers that the safety limit for driving is higher than $80 \mathrm{~km} / \mathrm{h}$ and they drive on average with $78 \mathrm{~km} / \mathrm{h}$. Most drivers (81\%) consider that the current posted speed limit is about correct and 
they drive on average with $76 \mathrm{~km} / \mathrm{h}$. Of the remaining drives, $13 \%$ consider that the speed limit is very low and must be increased and they travel at an average speed of $84 \mathrm{~km} / \mathrm{h}$. The remaining $6 \%$ consider that the speed limit is very high and must be decreased and their mean speed is $74 \mathrm{~km} / \mathrm{h}$.

Almost $60 \%$ of the drivers consider that the speed limit must not be exceeded and that it can be exceeded in certain occasions. Three fourths of the drivers consider that the speed limit is lower than the safety speed and can be exceeded up to $10 \mathrm{~km} / \mathrm{h}$. The mean speed for those drivers is about $77 \mathrm{~km} / \mathrm{h}$. Of the remaining drivers, $17 \%$ believe that the speed limit is lower than the safety speed and can be exceeded by more than $10 \mathrm{~km} / \mathrm{h}$. The mean speed for those drivers is about $75 \mathrm{~km} / \mathrm{h}$.

\subsection{Speed Measurements}

Speeds were collected at various locations representing the speeds for the roadway segments where drivers were interviewed. Such speed measurements could be used as an indicator of the drivers' compliance with the posted speed limits. These measurements also present a fundamental relationship between operating speeds and the various elements of the roadway geometry, such as vertical and horizontal curves, roadside environment, and cross section elements. Various locations were selected for these sped measurements at different spots of the Greek National Highway System. These sites were selected based on the roadway geometry, the cross section elements, the roadway environment, and the existing posted speed limits. A summary of the measurements is presented in Table 1.

Speed measurements have shown thatdrivers of passenger cars and trucks exceed the posted speed limit by various magnitudes. All feel that the posted speed limit could be safely exceeded and all believe that posted speed limits are set to improve safety. Even though most drivers agree with the notion that the posted speed limits should be obeyed, they tend to drive at speeds greater than the posted speed limits and that a range of $10 \mathrm{~km} / \mathrm{h}$ is an acceptable value.

Overall, truck drivers have a more appropriate attitude towards speed limits. More of them tend to drive closer to the speed limits and their 85 th percentile speeds tend to remain close (both in numbers and percentages) the posted speed limits.

The findings of the survey lead to the conclusion that a more systematic approach is needed to establish speed limits that are reflective of the roadway geometry and produce operating speeds that are in harmony with it.

\section{Greek Guidelines for Setting Speed Limits}

The guidelines developed include the major principles, criteria and data for setting and verifying the local speed limits based on road safety criteria [2]. These guidelines are based on the following principles: - the use of a rural road needs continuous attention and mutual respect from all users;

- the driver selects a speed in order to control his/her vehicle with safety;

Table 1 Spot speed measurements on specific locations of the Greek road network.

\begin{tabular}{|l|l|l|l|l|l|l|}
\hline Road class & $\begin{array}{l}\text { Horizontal } \\
\text { curve }(\mathrm{m})\end{array}$ & Grade $\%$ & $\begin{array}{l}\text { Local speed } \\
\text { limit }(\mathrm{km} / \mathrm{h})\end{array}$ & $\begin{array}{l}\text { V85, Vm passenger } \\
\text { cars }(\mathrm{km} / \mathrm{h})\end{array}$ & $\begin{array}{l}\text { V85, Vm, V15 } \\
\text { trucks }(\mathrm{km} / \mathrm{h})\end{array}$ & $\begin{array}{l}\text { V85, Vm, V15 } \\
\text { buses }(\mathrm{km} / \mathrm{h})\end{array}$ \\
\hline 2 lane rural road & 450 & 0.5 & 60 & 100,87 & $78,71,61$ & \\
\hline 2 lane rural road & 415 & 1.0 & 80 & 100,87 & $78,71,64$ & $82,75,66$ \\
\hline 2 lane rural road & 1025 & 0.5 & 110 & 130,115 & $82,80,68$ & $94,-, 79$ \\
\hline 2 lane rural road & Tangent & 0.5 & 50 & 77,68 & $67,59,51$ & \\
\hline 2 lane rural road & Tangent & 2.5 & 50 & 116,101 & $86,73,62$ & \\
\hline Freeway & Tangent & 2.0 & 120 & 144,132 & $89,84,78$ & 98 \\
\hline
\end{tabular}

Notes: V85: the 85th percentile speed; Vm: the average speed; V15: the 15th percentile speed. 
- the vehicle speed should be adapted to road conditions, vehicle operation, driver's skill, visibility, traffic flow and weather conditions;

- the speed limit is set only for cases where a driver paying full attention to the roadway cannot perceive the safe speed related to this section; and the maximum speed is restricted by available sight distance so that safe stopping is possible.

\subsection{Criteria for Setting Speed Limits}

Setting speed limit is the last action for transportation agencies only in case that they have exhausted or excluded anyengineering intervention on the road infrastructure that should make speed limit not necessary. This rule is applicable for existing, new and under construction (or design) roads excluding at-grade intersection areas.

The cases where establishing speed limits should be considered are:

- At grade intersections along high speed roads. The speed limit on rural at-grade intersections (signalized or non-signalized) should not exceed $70 \mathrm{~km} / \mathrm{h}$.

- Sections with limited sight distance conditions.

- Curved sections where low vehicle speeds are required based on the principles of vehicle dynamics, sections where horizontal curves are combined with high downgrades and areas with deteriorated pavement surface.

- Weaving areas where the traffic streams merge or diverge.

- Sections where pedestrians or cyclists move parallel to the major road and sections with high number of pedestrian or cyclist accident records.

- Sections that approach or pass through urban areas, or sections where low speeds are required for any technical reason (sometimes this reason may not be obvious or comprehensive to all drivers).

- Hazardous locations based on accident data ("black spots") where the warning signs have been proven insufficient. In this case the speed limit must be estimated for wet pavement conditions.
- Upgrade sections with significant differential speed (speed variance) between cars and trucks.

- In areas with high pedestrian volumes crossing the major road. In this case the speed limit is set to 50 $\mathrm{km} / \mathrm{h}$.

- In areas where the operational speed is not anticipated or rightly perceived by the road users (including pedestrians).

Setting any speed limit requires consideration of the preceding road sections. Attainment of a significantly lower speed limit than the speed level of the preceding section is made at $20 \mathrm{~km} / \mathrm{h}$ steps per ca $200 \mathrm{~m}$.

In most cases the speed limit should correspond to 85th percentile speed rounded in increments of ten. If the speed limit must be set lower than the above value for technical reasons then it should be controlled by consistent enforcement. On several occasions the establishment of speed limit must be combined with overtaking restriction.

Speed zoning should avoid frequently changes of speed limits.

Speed limit sign is placed at most $150 \mathrm{~m}$ before the critical location of limit application.

\subsection{Speed Zones}

Speed zoning is the process of establishing a reasonable and safe speed limit for a section of roadway where the statutory speed limits given for a specific motor vehicle type do not fit the road or traffic conditions at a specific location [4]. The limits may be altered on the basis of an engineering study.

In addition, speed limits that are increased or decreased as a result of the speed zoning process must be recorded in documents maintained by an appropriate agency. Speed zones should be periodically revisited and evaluated. As a general rule every 10 years all speed zones should be re-assessed to determine their appropriateness and functionality.

The basic principles of speed zoning should also be applied to special situations such as school crossings and roadway construction areas. In addition, speed 
zoning includes the procedure for establishing minimum speed limits on freeway sections.

\subsection{Speed Limits for New Rural Roads}

The criteria mentioned above are also applicable for new rural roads (under construction or under design). The traffic signing design should suggest temporary speed limits. The Agency responsible for the operation and the maintenance of the road must work out a speed zone study. Current regulations require that a study for setting speed zones is an integral and essential part of highway designs and the resultant speed limits are in force for a maximum period of 10 years, provided that accident data do not impose a change of speed limits in a shorter period.

Design consistency ensures that successive geometric elements act in a coordinated way, so that they produce harmonized driving performances consistent with driver expectations [4]. Safety criteria is a tool to evaluate design consistency especially on two lane rural roads. The application of Safety Criteria as mentioned in Greek Guidelines for Design of Road Projects will eliminate the necessity for setting speed limits [5]. These criteria supplemented by adoption of the "forgiving" roadside environment principle will reduce the number of severe crashes.

\subsection{Speed Limits for Existing Rural Roads}

\subsubsection{Freeways}

The speed value of $60 \mathrm{~km} / \mathrm{h}$ is the minimum speed limit that can be applied on freeways.

Local speed limits between $60 \mathrm{~km} / \mathrm{h}$ and $130 \mathrm{~km} / \mathrm{h}$ are set where it is necessary. In this case the speed limit is combined with an additional sign that explains the reasoning for the posted speed limit or an additional sign with the speed limit related to specific conditions, e.g., wet pavement. If one or more of the traffic lanes have length equal to $3.25 \mathrm{~m}$ then the maximum speed limit is $100 \mathrm{~km} / \mathrm{h}$. Generally, each speed level (rounded in $10 \mathrm{~km} / \mathrm{h}$ ) should differ from the following grade by $20 \mathrm{~km} / \mathrm{h}$. The minimum distance between two speed grades is $200 \mathrm{~m}$.
The above speed limits can eliminate dangerous driving conditions and traffic congestion. A list of candidate areas for setting local speed limits includes the following:

- Long length downgrade sections;

- Long length upgrade sections (to avoid significant;

- Differential speed between passenger cars and heavy vehicles);

- Curved sections with high curvature; and

- Sections with slippery pavement.

Often the minimum speed limits differ for each traffic lane. Setting minimum speed limit only on the left traffic lane (overtaking lane) is an efficient practice for increasing safety.

\subsubsection{Two Lane Rural Roads}

The continuous and unnecessary restriction of speed is not a good practice. Speed restrictions must be imposed only by roadway and traffic conditions. Speed limits must be perceived by the travelling public as "reasonable", that is, as consistent with the enforced traffic conditions experienced by the typical driver. To the extent that this is not true, more drivers will be non compliant, which could compromise highway safety.

The speed limits on rural roads should be explained and justified by additional signs (Fig. 1).

The pavement condition is a reason for setting conditional speed limits (when the pavement is wet). In this case instead of the speed limit mandatory sign, the sign for wet pavement is added as well (Fig. 2). The speed limit on rural areas is mostly $60 \mathrm{~km} / \mathrm{h}$ or $80 \mathrm{~km} / \mathrm{h}$.

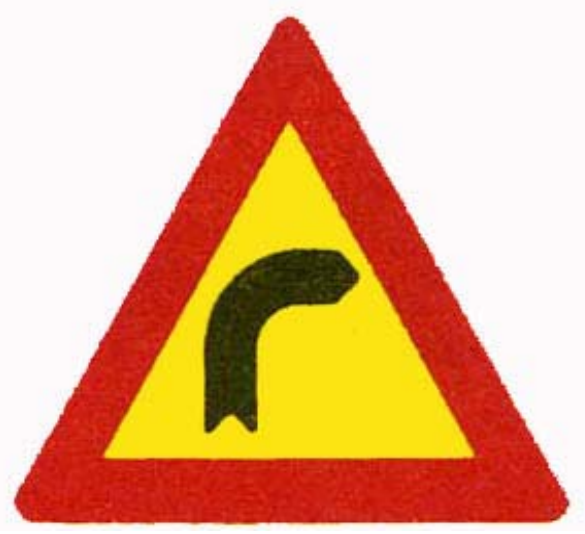

Fig. 1 Warning sing combined with speed limit. 


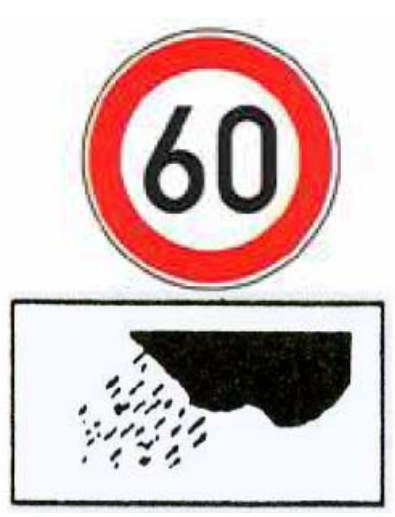

Fig. 2 Speed Limit only when the pavement is wet.

The beginning and the end of the speed limit application area as well as the speed limit value itself may differ between opposing directions. Provided that the difference between the two speed limits does not exceed $10 \mathrm{~km} / \mathrm{h}$, it is acceptable to equalize speed limits for both directions of travel to the minimum speed limit for better enforcement purposes.

If the speed restriction is in force for sections of considerable length, the length that the speed limit is in force is shown by an additional sign.

Elements such as trees, fences, shrubbery or similar along the road have the potential to influence the operating speeds and therefore the corresponding speed limit. In this case the speed limit is related to the lateral clearance (Table 2).

\subsection{Abutting Land Access}

The problem for setting speed limits in relation to the roadside development relates to the concept of access management. The establishment of the appropriate speed limit is necessary when the differential speeds between the through traffic and the generated traffic by the roadside accesses are significant enough to compromise road safety.

The speed limits presented on Table 3 are set as a function of ingress/egress distance.

Table 2 Speed Limit for two lane rural roads related to lateral clearance.

\begin{tabular}{|c|c|c|c|}
\hline Speed Limit $(\mathrm{km} / \mathrm{h})$ & $\leq 50$ & $\leq 70$ & $>70$ \\
\hline Length of lateral clearance $(\mathrm{m})$ & 0.75 & 1.00 & 1.25 \\
\hline
\end{tabular}

Table 3 Speed Limits along roads with roadside development.

\begin{tabular}{|l|l|l|}
\hline \multirow{2}{*}{$\begin{array}{l}\text { Maximum Speed } \\
\text { Limit }(\mathrm{km} / \mathrm{h})\end{array}$} & \multicolumn{2}{|l|}{ Distance between access $(\mathrm{m})$} \\
\cline { 2 - 3 } & Rural \& suburban roads & $\begin{array}{l}\text { Urban } \\
\text { roads }\end{array}$ \\
\hline 70 & 350 & - \\
\hline 60 & 300 & - \\
\hline 50 & $\leq 250$ & $\leq 250$ \\
\hline$\leq 50$ & $\leq 200$ & $\leq 200$ \\
\hline
\end{tabular}

\section{At-grade Intersections and Interchanges}

The speed limit for rural non signalized at-grade intersections is $70 \mathrm{~km} / \mathrm{h}$ in order to avoid severe crashes. For high risk at-grade intersections the posted speed limit should be controlled by automated enforcement speed equipment (speed cameras).

The speed limit for rural signalized at-grade intersections is $70 \mathrm{~km} / \mathrm{h}$ in order to ensure safe stopping of a vehicle.

For both cases the posted speed limit ahead of the functional intersection area (maneuvering area for turning movements) is reduced gradually.

The speed limits for interchanges are based on the type, the determinative speeds (design speed, operating speed, and transition entry/exit speed) and the weaving type of through and ingress-egress traffic stream. Table 4 contains the proposed speed limits for through traffic stream without conflicts and Table 5 with conflicts. For urban freeways where entry /or exit stream is located on right turn curves with radius less than $500 \mathrm{~m}$, the speed limit of through traffic stream decreases to 60 $\mathrm{km} / \mathrm{h}$.

Table 6 contains the proposed speed limits for ramps related to the minimum inner curve radius and up to a grade of $5 \%$.

The selection of the advisory speed (or the speed limit) for curved ramp sections - especially on exit ramps - requires high attention and is related with following parameters:

- Geometric features of the ramp (curvature, superelevation, gradient, visibility);

- Weather conditions in combination with friction and vehicle type when the determinative speed values range between 30 and $40 \mathrm{~km} / \mathrm{h}$. 
Table 4 Speed Limits (proposed) for through traffic stream on interchange by roadway classification and cross section type (without conflict points).

\begin{tabular}{|l|l|l|}
\hline Roadway Functional Classification & Cross Section Type & Proposed Speed Limit (km/h) \\
\hline Rural Freeways /High Speed Highways & $\begin{array}{l}\text { divided } \\
\text { undivided }\end{array}$ & $\begin{array}{l}130120110 \\
10090\end{array}$ \\
\hline Rural Roads between regions /counties & divided & 110100 \\
\hline Rural Roads between cities/towns & divided & 10090 \\
\hline Urban Freeway / Urban High Speed Road & divided & 9080 \\
\hline
\end{tabular}

Table 5 Speed Limits (proposed) for through traffic stream on interchange (with conflict points).

\begin{tabular}{|c|c|c|c|c|}
\hline \multirow[t]{6}{*}{ Weaving Type } & $\begin{array}{c}\text { Weaving Length } \\
{[\mathrm{m}]}\end{array}$ & Area & Comments & $\begin{array}{c}\text { Speed Limit } \\
{[\mathrm{km} / \mathrm{h}]}\end{array}$ \\
\hline & 200 & \multirow{2}{*}{$\begin{array}{c}\text { Rural } \\
\& \\
\text { Urban }\end{array}$} & \multirow{2}{*}{$\begin{array}{c}\text { Cloverleaf } \\
\text { interchange type }\end{array}$} & 100 \\
\hline & 180 & & & 80 \\
\hline & 250 & \multirow{2}{*}{$\begin{array}{c}\text { Rural } \\
\& \\
\text { Urban }\end{array}$} & \multirow{3}{*}{$\begin{array}{l}\text { between two } \\
\text { interchanges }\end{array}$} & 100 \\
\hline & 200 & & & 80 \\
\hline & 180 & Urban & & 60 \\
\hline
\end{tabular}

Table 6 Speed Limits (proposed) for interchange ramps as related to curve radius (max superelevation rate $6 \%$ ).

\begin{tabular}{|r|r|r|r|r|r|r|}
\hline Inner Curve Radius $(\mathrm{m})$ & 35 & 35 & 115 & 170 & 250 & $(340)$ \\
\hline Speed Limit $(\mathrm{km} / \mathrm{h})$ & 30 & 40 & 50 & 60 & & 70 \\
\hline
\end{tabular}

Legend: ( ) = exceptional values.

\subsection{Advisory Speeds}

Advisory speeds are set by informative signs and represent the desired speeds on curves, intersections or other locations where the design features or the physical road conditions restrict safety speeds below the maximum law or local posted speed that is set by the mandatory speed limit sign.

Advisory speeds are set on road sections where it is advisable to warn drivers for probable dangerous by exceeding the advisory speed. In this case the establishment of a speed limit by a mandatory sign is not commanding. Advisory speed mostly reflects the 85th percentile speed. The advisory speed sign is combined with an additional explaining sign (Fig. 3).

It is necessary to avoid setting an advisory speed which is close to the posted speed limit because it might raise confusion to drivers.

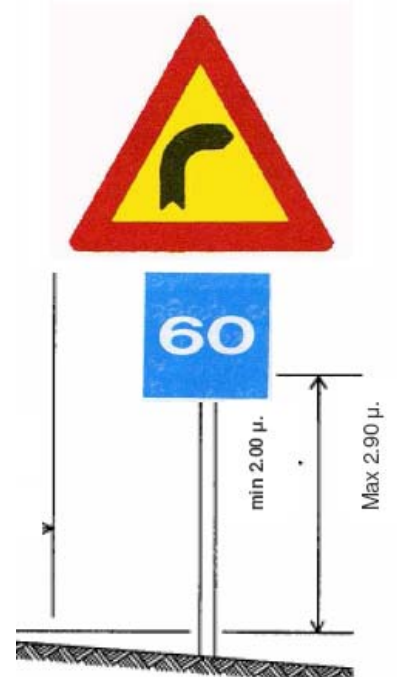

Fig. 3 Advisory speed limit combined with warning sign.

Advisory speed signs may be set at the flowing cases:

- intersectionswith restrict visibility on

- Narrow bridges and one lane bridges 
- $\quad$ Downgrades $(>6 \%)$

- Exit Ramps

\section{- Crest and Sag Vertical Curves}

The guidelines for setting reliable speed limits in Greek rural roads forms the basis for assessing the existing local speed limits along the national and provisional roads. In this respect it is expected that a significant contribution will have been made for reducing fatalities and injuries in the country. As a matter of fact the accident records of the country in the last 5 years show a decrease in fatality rates

\section{Discussion}

This paper presented a two-step process followed in Greece for establishing a methodology for setting appropriate speed limits for rural roads. The first step focused on the understanding of the attitudes of drivers towards speed limits while the second used these attitudes to setup guidelines for setting appropriate speed limits.

In general, drivers indicated that speed limits on freeways are lower than what should be. The speed measurements also indicated that the 85th percentile speed is higher than the posted speed limit. Therefore, a new speed limit of $130 \mathrm{~km} / \mathrm{h}$ was set for freeways. For other rural roads, the previous speed limit was 100 $\mathrm{km} / \mathrm{h}$ and the new rules differentiate between express rural, two-lane roads with a new speed limit of 110 $\mathrm{km} / \mathrm{h}$ and all other rural two-lane roads with a $90 \mathrm{~km} / \mathrm{h}$ speed limit. The fact that drivers typically exceed the posted speed limits and this violation varies among the different roadway types resulted in considering and setting specific speed limits for each roadway class. The posted speed limits are set based on the assumption that they have to be similar to the operating speed (V85) and should not significantly exceed it. Fears that this increase would also increase crash rates and frequencies have not been validated based on the crash data reviewed since the increase of the speed limit. For the 2009-2010 period when the new speed limits had been in full effectan overall13\% decrease on crash frequencywas observed. Similarly, for rural roads an $8 \%$ decrease in crashes was also observed for the 2006-2009 period, which was after the enforcement of the new speed limits for rural roads [7].

A new approach based on the survey findings is also the concept that for new roads no posted speed limits will be placed once the roadway is opened to traffic unless there is specific reason to introduce a local speed limit like a design exception for example. Speed studies will be conducted to estimate 85 th percentile speeds and speed limits will be set based on the findings of the study, if needed.

The findings from this survey indicate that, in general, drivers feel that the posted speed limits can be exceeded at certain situations and they believe that a range of $10 \mathrm{~km} / \mathrm{h}$ is an acceptable value. The results of the survey indicate that the roadway environment plays a more important role than the posted speed limit in selecting the appropriate operating speed. This leads to the basic conclusion that often times posted speed limits are placed without the proper considerations and are implemented due to a variety of reasons often unrelated to the roadway environment (statutory speed limits on freeways is such an example). This lead to the use of advisory speed signs, such as those shown in Fig. 3, which consider environmental conditions. The driving code has to be changed with this respect to comply with this aspect.

The survey results indicate that it is imperative that a more systematic approach is needed to establish speed limits that are reflective of the roadway geometry and produce operating speeds that are in harmony with the roadway environment. The new methodology developed for Greek rural roadways addresses these concepts and is a first step in the right direction of setting reasonable speed limits.

\section{References}

[1] Research Association for Road and Traffic Engineering, Guide for the design of motorways (RAA), Cologne, Germany 2008.

[2] Ministry of Environment, Physical Planning and Public Works, Development of speed management procedures 
for the Greek road network, National Technical University of Athens, Laboratory of Transportation Engineering, Athens, Greece, 2006.

[3] Managing speed, TRB Special Report 254, National Research Council, Washington, D.C., 1998.

[4] Design speed, operating speed and posted speed limits, NCHRP 504, TRB, Washington, D.C., 2003.

[5] R. A. Krammes et al., Horizontal alignment design consistency for rural two lane highways, Rep. No. FHWA-RD-94-034, F.H.W.A., Washington, D.C..
[6] Ministry of Environment, Regional Planning and Public Works, Guidelines for design of road projects, Part 3, Alignment, 2001.

[7] European Commission - Directorate - General for energy and Transport Energy and Transport, CARE Database, 15.5.2011, available online at: http://ec.europa.eu/transport/road_safety/specialist/statisti cs/care_reports_graphics/index_en.htm. 